\title{
Structural variation in Xq28: MECP2 duplications in $1 \%$ of patients with unexplained XLMR and in $2 \%$ of male patients with severe encephalopathy
}

Dorien Lugtenberg ${ }^{1}$, Tjitske Kleefstra*, ${ }^{*}$, Astrid R Oudakker ${ }^{1}$, Willy M Nillesen ${ }^{1}$, Helger G Yntema ${ }^{1}$, Andreas Tzschach ${ }^{2}$, Martine Raynaud ${ }^{3}$, Dietz Rating ${ }^{4}$, Hubert Journel ${ }^{5}$, Jamel Chelly ${ }^{6}$, Cyril Goizet ${ }^{7}$, Didier Lacombe ${ }^{7}$, Jean-Michel Pedespan ${ }^{7}$, Bernard Echenne ${ }^{8}$, Gholamali Tariverdian $^{9}$, Declan O'Rourke ${ }^{10}$, Mary D King ${ }^{10}$, Andrew Green ${ }^{11}$, Margriet van Kogelenberg ${ }^{12}$, Hilde Van Esch ${ }^{13}$, Jozef Gecz ${ }^{14}$, Ben CJ Hamel ${ }^{1}$, Hans van Bokhoven ${ }^{1}$ and Arjan PM de Brouwer ${ }^{1}$

\footnotetext{
${ }^{1}$ Department of Human Genetics, Radboud University Nijmegen Medical Centre, Nijmegen, The Netherlands; ${ }^{2}$ Department of Human Molecular Genetics, Max Planck Institute for Molecular Genetics, Berlin-Dahlem, Germany; ${ }^{3}$ Service de Génétique, CHRU de Tours, Tours, France; ${ }^{4}$ Department of Paediatric Neurology, University Children's Hospital, Heidelberg, Germany; ${ }^{5} \mathrm{CH}$ de Vannes, Génétique Médicale, Vannes, France; ${ }^{6}$ Institut Cochin (IC), Département de Génétique et Pathologie Moléculaire GDPM, Equipe de Génétique et Physiopathologie du Retard Mental GPRM, Paris, France; ${ }^{7}$ Service de Génétique Médicale, Hôpital Pellegrin-Enfants, CHU de Bordeaux, France; ${ }^{8}$ Service de Neuropédiatrie Hôpital Saint-Eloi, CHU de Montpellier, France; ${ }^{9}$ Institute for Human Genetics, University Heidelberg, Heidelberg, Germany; ${ }^{10}$ Children's University Hospital, Limited Liability Company (Limited by Shares), Dublin, Ireland; ${ }^{11}$ Our Lady's Hospital, Crumlin and The Children's University Hospital, Dublin, Ireland; ${ }^{12}$ Department of Paediatrics and Child Health, Dunedin School of Medicine, Otago University, Dunedin, New Zealand; ${ }^{13}$ Center for Human Genetics, University Hospital Leuven, Leuven, Belgium; ${ }^{14}$ Department of Genetic Medicine, Women's and Children's Hospital and Department of Paediatrics, University of Adelaide, Adelaide, Australia
}

Duplications in Xq28 involving MECP2 have been described in patients with severe mental retardation, infantile hypotonia, progressive spasticity, and recurrent infections. However, it is not yet clear to what extent these and accompanying symptoms may vary. In addition, the frequency of $\mathrm{Xq} 28$ duplications including MECP2 has yet to be determined in patients with unexplained $\mathrm{X}$-linked mental retardation and (fe)males with severe encephalopathy. In this study, we used multiplex ligation-dependent probe amplification to screen Xq28 including MECP2 for deletions and duplications in these patient cohorts. In the group of 283 patients with X-linked mental retardation, we identified three $\mathrm{Xq} 28$ duplications including MECP2, which suggests that approximately $1 \%$ of unexplained X-linked mental retardation may be caused by MECP2 duplications. In addition, we found three additional MECP2 duplications in 134 male patients with mental retardation and severe, mostly progressive, neurological symptoms, indicating that the mutation frequency could be as high as $2 \%$ in this group of patients. In 329 female patients, no Xq28 duplications were detected. In total, we assessed 13 male patients with a MECP2 duplication from six unrelated families. Moderate to severe mental retardation and childhood hypotonia was noted in all patients. The majority of the patients also presented with absent speech, seizures, and progressive spasticity as well as ataxia or an ataxic gait and cerebral atrophy, two previously unreported symptoms.

*Correspondence: Dr T Kleefstra, Department of Human Genetics, Radboud University Nijmegen Medical Centre, PO Box 9101 , Nijmegen 6500 HB, The Netherlands. Tel: + 3124361 3946; Fax: + 3124366 8753; E-mail: T.Kleefstra@antrg.umcn.nl

Received 2 May 2008; revised 25 July 2008; accepted 12 September 2008; published online 5 November 2008 
We propose to implement DNA copy number testing for MECP2 in the current diagnostic testing in all males with moderate to severe mental retardation accompanied by (progressive) neurological symptoms. European Journal of Human Genetics (2009) 17, 444-453; doi:10.1038/ejhg.2008.208; published online 5 November 2008

Keywords: MECP2; Xq28; XLMR; encephalopathy; duplications

\section{Introduction}

Genomic rearrangements including deletions and duplications are often related to disease. Cytogenetically visible deletions and duplications, are usually associated with a syndromic phenotype that comprises mental retardation (MR). Such complex phenotypes are brought about by the reduced or elevated expression of one or more dosagesensitive genes from the respective deleted or duplicated regions. Often it is not clear which gene or genes are accountable for the mental disabilities observed in the patients with a large duplication or deletion. In few cases, one gene can be held responsible for the major phenotypic characteristics seen in these patients. For instance, the $9 \mathrm{q}$-subtelomeric deletion syndrome can be attributed to haploinsufficiency of just one gene, EHMT1, that is located in the common deletion. ${ }^{1}$ Severe mental retardation, hypotonia, seizures and recurrent infections in male patients can be the result of duplications in $\mathrm{Xq} 28 .^{2}$ It is thought that elevated expression of specifically MECP2 is responsible for this phenotype. Screening for copy number changes of MECP2 in selected cohorts of patients has revealed $M E C P 2$ duplications in 44 males with severe neurological problems from 21 families. ${ }^{2-7}$ Besides apparently tandem duplications including Xq28, Sanlaville et $a l^{8}$ reviewed 19 cases in which the $\mathrm{Xq} 28$-duplicated region is involved in a complex rearrangement. These included translocations to other chromosomes and $\mathrm{Xp}-\mathrm{Xq}$ rearrangements. These patients and the patients with tandem duplications of MECP2 share a similar phenotype including severe developmental delay, hypotonia, seizures and recurrent infections.

Although a specific phenotype has been described for patients with MECP2 duplications, it is not yet clear to what extent the symptoms may vary. These could be related to other genes in the respective Xq28 duplications. In addition, the frequency of Xq28 duplications including MECP2 has yet to be determined in male patients with idiopathic X-linked MR (XLMR) and (fe)male patients with severe encephalopathy. Therefore, we screened a $1.3 \mathrm{Mb}$ region on Xq28 including the MECP2 gene for copy number imbalances to determine the frequency and size of duplications in this region in different cohorts of MR patients. Two groups of patients were tested: (1) 283 male probands from families with an X-linked inheritance pattern but no significant linkage interval and initially diagnosed as idiopathic XLMR, and (2) 134 male and 329 female patients with mental retardation and severe, mostly progressive, neurological symptoms. In total, we identified six novel MECP2 duplications in male patients from these two patient cohorts.

\section{Materials and methods Patients}

The patient cohort of 283 retarded males was collected by the European XLMR consortium (www.euromrx.com). Karyotypes at a resolution of 550 bands were normal and expansions of the CGG repeat in the 5 '-untranslated region of FMR1 were excluded. The 463 patients with severe encephalopathy were ascertained by the DNA diagnostics division of the department of Human Genetics, Radboud University Nijmegen Medical Centre, the Netherlands. This group consisted of 134 male and 329 female patients, who had been referred for screening of intragenic mutations in the MECP2 gene, because of features suggestive for Rett syndrome in women and severe encephalopathy in men. In none of the analyzed patients, point mutations in the MECP2 gene have been found by direct DNA sequencing of the coding region. All DNA samples were isolated from whole blood by the salting out method as described by Miller et al. ${ }^{9}$ Informed consent was obtained for all patients.

Multiplex ligation-dependent probe amplification For testing of EuroMRX patients, 15 multiplex ligationdependent probe amplification (MLPA) probes were used, which specifically match the coding sequence of 12 genes from the critical region in Xq28 (Table 1). MLPA probes were designed and MLPA reactions were performed as described earlier. ${ }^{10}$ Additional probes elsewhere on the $\mathrm{X}$ chromosome and autosomes were used for quality control. ${ }^{10}$ In addition, the commercial SALSA MLPA kit P015C for testing copy number variations of MECP2 (MRC Holland, Amsterdam, The Netherlands) was used for validation and fine mapping. The patients with severe encephalopathy were tested in a DNA diagnostic setting using the commercial P015C MLPA kit.

\section{Results}

MLPA analysis

The index patient of each of the 283 EuroMRX families was tested for copy number variations in the Xq28 region with MLPA probes in the following genes: TREX2, BGN, ATP2B3, 
Table 1 Probe sequences of MLPA probes

\begin{tabular}{|c|c|c|}
\hline Gene & Left probe $\left(5^{\prime} \rightarrow 3^{\prime}\right)$ & Right probe $\left(5^{\prime} \rightarrow 3^{\prime}\right)$ \\
\hline TREX2 & cccgggecgagacctttgtctt & cctggacctggaagccactggg \\
\hline$B G N$ & ctgtcccatgggcttcggggtgaag & cgggcctactacaacggcatcag \\
\hline ATP2B3 & cacgcttagcagctttctcaccgccg & ccaaaccttgcctgggcactgggacc \\
\hline DUSP9 & cttcagcagattccaggccgagtgccct & cacctgtgtgagaccagccttgctggcc \\
\hline PLXNB3 & cacttggcactggcacctggccgaggcaca & ctctatgtcggcgcagtgaaccgcctcttc \\
\hline ARHGAP4 & ggaaagacctctgtccgccagggecttgggcc & agcatctaccacctctcccagtcctgggeccc \\
\hline MECP2 & gaagagaaagagggcaagcatgagcccgtgcagccatcagccca & ccactctgctgagcccgcagaggcaggcaaagcagagacatcag \\
\hline MECP2 & caccagttcctgetttgatgtgacatgtgactccccagaatacacc & ttgcttctgtagaccagctccaacaggattccatggtagctgggat \\
\hline FLNA & tgcagtcagcctgaacggggcca & agggggcgatcgatgccaaggtg \\
\hline FLNA & gcgcagctcgagtgcttggacaatggggatggc & acatgttccgtgtcctacgtgcccaccgagccc \\
\hline FLNA & ccttcccctgccaggcatcgagcccacaggcaacatggtga & agaagcgggcagagttcactgtggagaccagaagtgctggc \\
\hline GDI1 & cctggetgeccgeccaggatacctgtctgactc & accctgggcgctgggctctggctgtttccaggtgttctg \\
\hline PLXNA3 & ctgggcaacaggccettccgtgccttcgtggtgacaga & caccacgcttacccacctggctgtgcaccgggtgactg \\
\hline FAM $3 A$ & ccgaggcgctggagatggaaggctgtatcccgcggagaag & cacggccagctagcacggccagtgccaggaccgggccgag \\
\hline GAB3 & ggtccttagtgagcctggacagagcaaggagagggctcccca & ctccctaagccccacagccagctctgcatcaccacaccacgc \\
\hline
\end{tabular}

DUSP9, PLXNB3, ARHGAP4, MECP2, FLNA, GDI1, PLXNA3, $F A M 3 A$ and $G A B 3$. Three probands carried a duplication of at least the MECP2 gene (Figure $1 \mathrm{~g}$; families $\mathrm{A}-\mathrm{C}$ ). The three duplications were confirmed by using the commercial MLPA probe kit from MRC Holland. In the 134 male patients with (progressive) neurological symptoms, three duplications of the MECP2 gene were identified (Figure 1g; families D-F). All 329 female patients with a Rett syndrome-like phenotype were negative for duplications in the Xq28 region. Also 178 control male samples were negative for duplications in the Xq28 region.

Family $\boldsymbol{A}$ A duplication of about $400 \mathrm{~kb}$ was found in family A (D033 in the EUROMRX cohort; www.euromrx. com) spanning the genomic region starting proximal of the ARHGAP4 gene to distal of the FLNA gene (Figure $1 \mathrm{~g}$ ). Family A consists of two brothers with severe mental retardation and one affected maternal uncle (Figure 1a). One other brother, III-8, was born prematurely at 25 weeks of gestation and died from a cytomegalovirus infection. All females were normal, except for the sister of the affected brothers who suffered from generalized epilepsy since the age of 12 years. Epilepsy was also present in another healthy maternal uncle and in a healthy brother of the maternal grandfather. The duplication was identified in both affected brothers and their mother, whereas the sister did not carry the duplication.

The index patient III-7 was born after a normal pregnancy and delivery with a birth weight of $3180 \mathrm{~g}$. During the first six months he developed normally, after which his development stagnated. He could sit without support at the age of 18 months and walk without help at the age of 3 years and 3 months. At three and a half years, he spoke four to five words, after which his ability to speak got worse with the passing of time. Since the age of 5 years, he experienced seizures classified as multifocal discharge or Lennox-Gastaut syndrome, which were difficult to control with medication. Because of frequent aspiration pneumonia, he was fed by a percutaneous endoscopic gastrostomy tube since the age of 8 years. On examination at the age of 14 years, his height was $140 \mathrm{~cm}(-3.5 \mathrm{SD})$ and his head circumference $52.9 \mathrm{~cm}(-1.5 \mathrm{SD})$. He had a mildly flat midface, slightly enlarged ears (Figure 2d), mild clinodactyly and contractures of several joints, such as the knees, hips, elbows, shoulders and wrist joints. He did not speak and showed an apparent loss of passive understanding of language. After a period of suffering from an ataxic gait, he became wheelchair bound as of the age of 9 years. Neurological investigation showed pyramidal signs with exaggerated deep tendon reflexes, Babinski and Trömner signs, and jerky myoclonus. In addition, the patient presented with axial hypotonia and peripheral hypertonia. Laboratory investigation showed normal IgG and subclass IgG1 levels and a secondary hypothyroidism. Brain MRI showed a small periventricular defect and broadened Virchow-Robin spaces.

The affected brother, III-9, was born after normal pregnancy and delivery with a birth weight of $3250 \mathrm{~g}$. His development was normal during the very first months, but thereafter his development stagnated as was seen in his brother. He was able to walk at the age of two and a half years, but after the age of 3 years his ability to walk regressed, because of slightly progressive truncal ataxia. At the age of 7 years only supported walking was possible. He never spoke a word. There were difficulties with eating and swallowing, but he had no aspiration pneumonia as his brother. At the age of 4 years, complex partial and grand mal types of seizures started. He showed a mildly flat midface and slightly enlarged ears (Figure 2e), mild contractures of knees with otherwise normal joints, hypotonia and mild jerky myoclonus.

Family B The Xq28 duplication in family B (P002 in the EUROMRX cohort; www.euromrx.com) had a minimum 
a

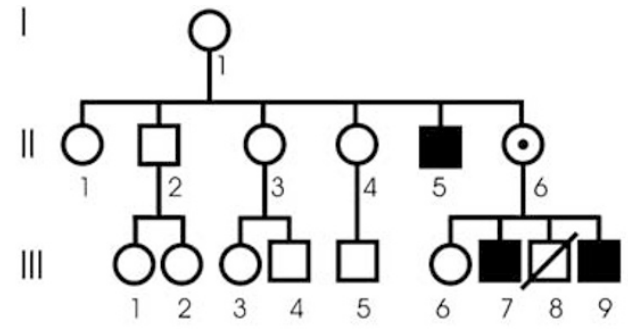

b

॥

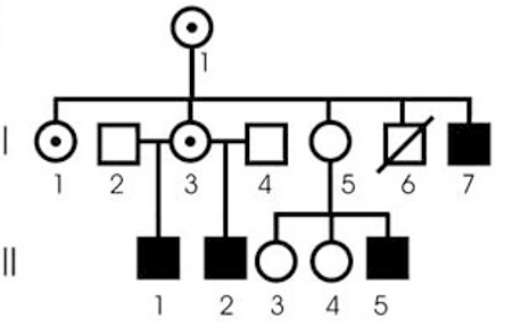

c

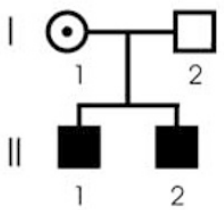

d

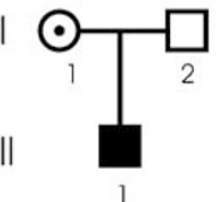

e

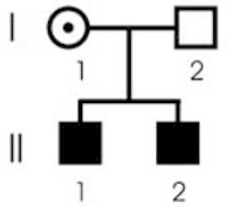

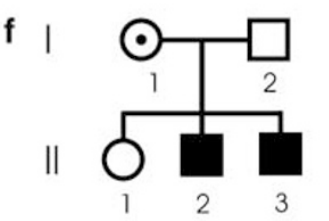

g
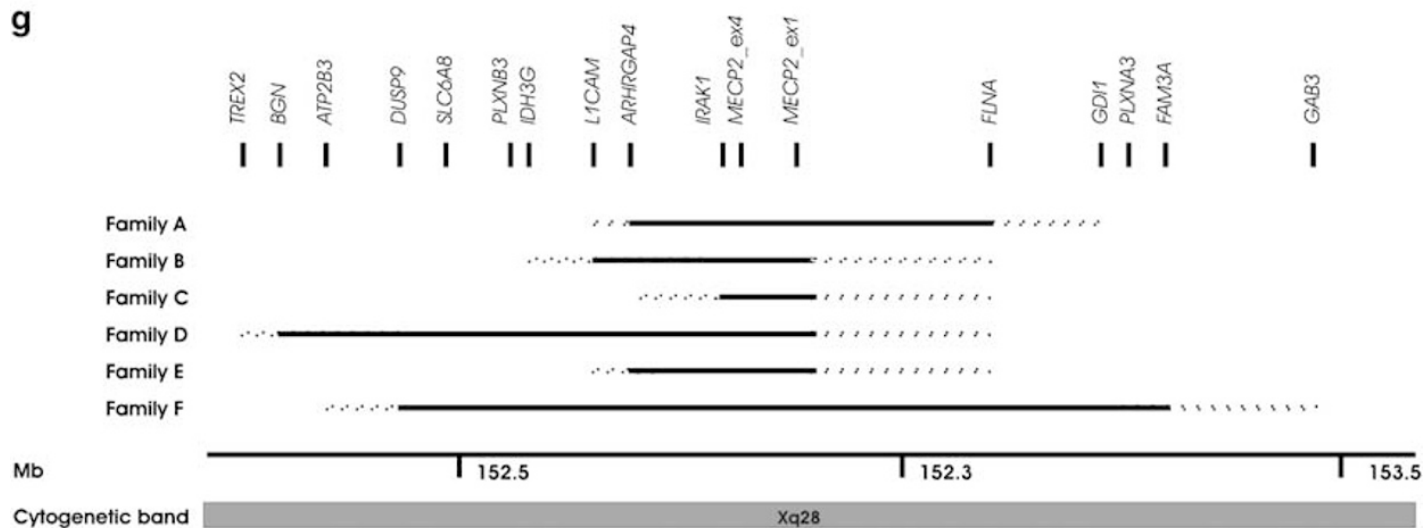

Figure 1 Schematic overview of the duplication mapping in the six affected families. (a-f) Pedigrees of the six affected families. (g) Detailed overview of the genomic region on the X chromosome surrounding MECP2. Genes tested by MLPA analysis are shown at the top. Black lines indicate the duplicated region and the dotted lines indicate the break point region between the last duplicated MLPA probe and the first probe with a normal copy number.

size of $260 \mathrm{~kb}$ and included L1CAM, IRAK1 and MECP2 (Figure 1g). Family B consists of four affected men in two generations and four carrier women (Figure 1b). Previous exclusion mapping excluded part of the $\mathrm{X}$ chromosome resulting in two possible disease-related regions: Xp11 and Xq28. All four affected boys were born after an uneventful pregnancy with normal birth parameters.

Patient II-7 showed delayed milestones with hypotonia. He could sit without support at the age of 12 months and walk alone at the age of 30 months. Initially, the only neurological abnormality was an ataxic gait, but in time progressive pyramidal signs with contractions of the hips and knees were reported. He had a moderate to severe mental deficiency with an estimated IQ below 50 . He did not speak. At the age of three and a half years, he presented with motor stereotypies and gaze deficit. During the first years of life, no dysmorphic features were noted, but progressively, a more evident dysmorphic facial appearance with large ears, broad nose, coarse facial appearance, open mouth and drooling was noted. His fingers and toes were very slender. He had epileptic seizures since 8 years of age, which were of the tonic-clonic generalized type at the onset, but rapidly became tonic, a-tonic, or myoclonic. At the age of 12 years, he had a normal head circumference, but his cerebral MRI showed a moderate cerebral atrophy with a hypersignal of the white matter in the posterior parts of the cerebral hemispheres, associated with moderate superior vermis atrophy. After the age of 15 years, it was apparent that the neurological abnormalities got worse. The pyramidal signs progressed, the ataxia persisted and he developed mood disorders with aggressive behavior, very severe drugresistant epilepsy with drop attacks, but no myoclonus, and frequent and daily falls needing the use of a helmet and a wheel chair. EEG recordings showed abnormal background activity, with slow waves and interictal generalized and/or focal discharges of the myoclonic type.

Patient III-1 seemed less severely affected. His development was delayed. He walked without support when he was 30 months old and did not speak. His total IQ was 50 . 

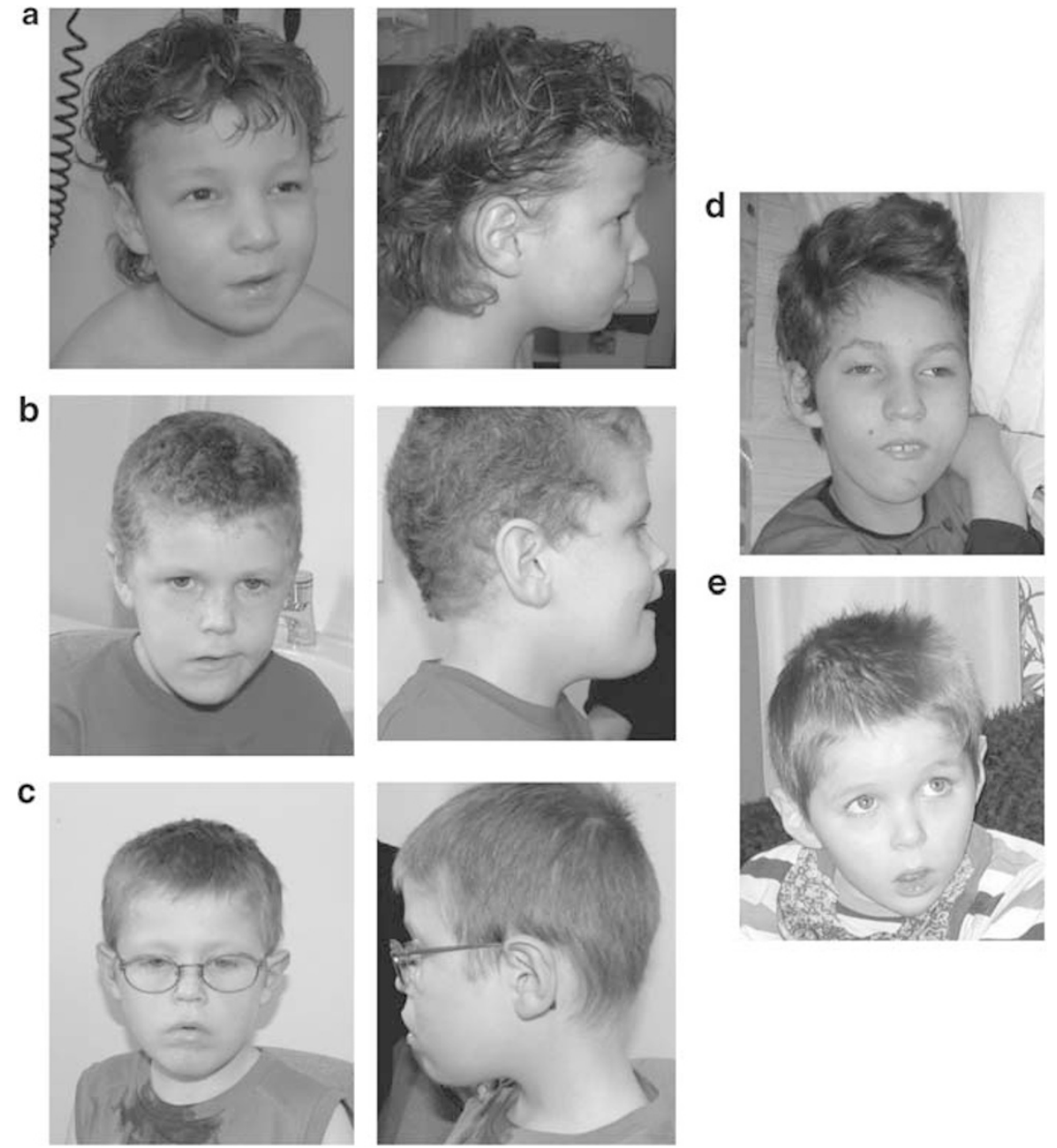

Figure 2 Photographs of five patients with a MECP2 duplication. (a) Patient II-1 from family D at the age of 8 years. (b) Patient II-1 and (c) patient II-2 of family E at the age of 11 and 8 years, respectively. (d) Patient III-7 and (e) patient III-9 of family A at the age of 14 and 7 years, respectively. Note high forehead, small nose, deep-set eyes, large ears, eversion of lower lip and/or prominent chin in several patients.

He had a normal head circumference, slightly progressive dysmorphic features comprising large ears, broad nose, coarse facial appearance and slender fingers and toes, similar to those of patient II-7. He had mild ataxia, no pyramidal signs, and no mood disorders. Since the age of 18 years, he had developed generalized seizures. A cerebral MRI was performed at the age of 7 years and showed the same abnormalities as in his uncle, such as moderate cortical atrophy, hypersignal of the posterior part of the cerebral white matter but with a normal cerebellum.

Patient III-2 also had early-onset generalized hypotonia with delayed milestones. He could walk without support after 24 months, had moderate ataxia, could not speak, had dysmorphic facial signs similar to those of his uncle, and developed epilepsy, which started at the age of 10 years. The epilepsy was drug resistant with myoclonic seizures and drop attacks. EEG recordings and cerebral MRI showed abnormalities similar to those that were seen in patient II-7.

Patient III-5 had delayed milestones as well. At the age of 6 years he was mentally retarded, did not speak, had ataxia but had a normal facial appearance. No seizures have been observed yet.

Family C In family C (T065 in the EUROMRX cohort; www.euromrx.com), the duplication had a minimal size of $100 \mathrm{~kb}$ and included solely MECP2 and IRAK1 (Figure 1g). The two affected brothers were born after an uneventful pregnancy with normal birth parameters (Figure 1c). They both presented with moderate mental retardation, hypotonia, and macrocephaly. Metabolic studies and cerebral imaging were normal in the two boys.

The index patient II-1 was born at term with a weight of $3580 \mathrm{~g}$, a height of $52 \mathrm{~cm}$, and a head circumference of 
$34.5 \mathrm{~cm}$. His development was delayed. He developed a social smile at the age of 2 months, was able to sit without support at the age of 17 months, started walking at the age of 2 years, and could only speak after the age of 5 years. At the age of 12 months, increased peripheral muscle tone and axial hypotonia was noted. Macrocephaly was obvious at two and half years (head circumference of $52 \mathrm{~cm},+2.4$ $\mathrm{SD})$. He developed ataxia at the age of 5 years. He experienced severe infections, such as pneumonia and meningitis. Since the age of 15 years, he suffered from absence type of seizures that did not respond to antiepileptic treatment.

Patient II-2 was born at term with a weight of $3550 \mathrm{~g}$, height of $49.5 \mathrm{~cm}$ and head circumference of $35.5 \mathrm{~cm}$. His development was delayed as well. He could sit alone at the age of 18 months, started walking at the age of 2 years, and developed speech at the age of 6 years. Axial hypotonia was noted in infancy. His head circumference was $53.5 \mathrm{~cm}$ $(+3.2 \mathrm{SD})$ at the age of 2 years and 10 months. He had ataxia and unsteady gait. Neither severe infections nor seizures were reported.

Family $D$ In family D, a duplication of about $600 \mathrm{~kb}$ including the $B G N, A T P 2 B 3, D U S P 9, S L C 6 A 8, P L X N B 3$, IDH3G, L1CAM, ARHGAP4, IRAK1 and MECP2 genes was identified in an 8-year-old boy with a severe mental retardation (Figure $1 \mathrm{~g}$ ). He was born from healthy nonconsanguineous parents and had a healthy older sister (Figure 1d). There were no other mentally retarded patients in the family. He was born after an uneventful pregnancy with a birth weight of $2500 \mathrm{~g}$. His development was severely delayed. He started walking at the age of three and a half years. He developed no speech. As an infant, he had esophageal reflux and generalized hypotonia was noted. Up to the age of 5 years, he had several episodes of severe respiratory infections with, at one time, admission to the intensive care unit. He had no seizures. His height, weight and head circumference were normal. On physical examination at the age of 8 years, facial hypotonia with excessive drooling, lateral flaring of eyebrows (Figure 2a), clinodactyly, fetal pads and short and broad feet were noted. Tendon reflexes were close to normal. Metabolic screening including creatine measurements in urine and spinal fluid were normal. Cerebral MRI and CTscan revealed cerebral atrophy.

Family $\boldsymbol{E}$ In family E, a duplication of about $200 \mathrm{~kb}$ including the ARHGAP4, IRAK1 and MECP2 genes was identified in a boy with severe neurological problems (Figure 1g). This boy had an affected brother as well (Figure 1e). Both patients were born after an uneventful pregnancy with normal birth parameters. They had severe psychomotor retardation. At the age of 8 years, patient II-1 had developed severe seizures and was also found to be hypothyroid for which he received L-thyroxine treatment.
A brain MRI at the age of 10 years did not show abnormalities. At the age of 11 years (Figure $2 \mathrm{~b}$ ), he spoke some words, was hypotonic and could walk only a few steps, with an ataxic gait. He was incontinent. His height, weight and head circumference were all normal.

Patient II-2 had a weight of $12.5 \mathrm{~kg}(+1.5 \mathrm{SD})$, a height of $82 \mathrm{~cm}(+2 \mathrm{SD})$, and a head circumference of $46 \mathrm{~cm}(0$ $\mathrm{SD})$ at the age of 1 year. At the last clinical examination at the age of 8 years (Figure 2c), he was hypotonic, had developed no speech and was not toilet-trained. He could just walk unaided but with an ataxic gait. He had no seizures. His brain CT was normal. His EEG showed mild generalized dysrhythmia. Blood amino acids, lactate, pyruvate, and acid-base studies, were normal in both brothers.

Family $\boldsymbol{F}$ In family $\mathrm{F}$, a duplication of about $900 \mathrm{~kb}$ including the DUSP9, SLC6A8, PLXNB3, IDH3G, L1CAM, ARHGAP4, IRAK1, MECP2, FLNA, GDI1, PLXNA3 and $F A M 3 A$ genes (Figure 1g) was identified in an eight-yearold boy with severe learning disability and epilepsy. This boy had an affected younger brother and a healthy older sister (Figure 1f). Both patient II-2 and patient II-3 were born to healthy unrelated parents after an uneventful pregnancy and did not have any perinatal problems. A maternal uncle died in infancy and a maternal granduncle was described as 'slow' but no further details are available.

Patient II-2 presented with severe learning disability, postnatal deceleration of head growth, bruxism, stereotypes, breath holding, recurrent severe respiratory infections, fluctuating dyskinesia, unsteady gait and loss of mobility at the age of 9 years. He was known with severe bowel constipation. At the age of 8 years, epilepsy started. EEG showed generalized spike waves and MRI showed ventricular dilatation and patchy signal abnormality in the deep white matter. Metabolic tests including creatine measurements in urine and cerebral spinal fluid were normal.

Patient II-3 had a milder phenotype. He started walking independently at the age of 3 years, developed minimal speech, and functioned in the moderate to severe learning disability range. Similar dysmorphisms as in his brother were noted. He had severe constipation problems as well. He had no postnatal fall off in head growth, severe infections, epilepsy, nor dyskinesia. MRI at 6 years showed general ventricular dilatation with signal change in the deep white matter, albeit less severe than in his brother.

\section{Discussion}

In a cohort of 283 mentally retarded patients with likely $\mathrm{X}$-linked mode of inheritance, we identified three duplications in Xq28, which all included the MECP2 gene. This indicates that the MECP2 duplication incidence could be as high as $1 \%$ in this group of patients. Moreover, we 
identified three duplications in 134 male patients with mental retardation and severe, mostly progressive, neurological symptoms, indicating that the mutation frequency could be as high as $2 \%$ in male patients with severe encephalopathy. In the cohort of 329 female patients with features suggestive of Rett syndrome, no MECP2 duplications were identified. In addition, the female relatives from the affected male patients who carried a Xq28 duplication were all healthy. It thus appears that MECP2 duplications do not lead to mental retardation in women. This is likely caused by skewing of X-inactivation, which has invariably been observed in women with a MECP2 duplication until now. ${ }^{2,4-6}$

The duplications range from approximately $100-900 \mathrm{~kb}$ in size and all include at least the MECP2 and the IRAK1 genes. The overall severity of the phenotype does not seem to correlate with the size of the duplication (Table 2). The phenotype of patients from family $\mathrm{C}$ with the smallest duplication is as severe as that of the other patients. Yet, the phenotype of patients of family $\mathrm{F}$, who had the largest duplication, was the most severe. One of the patients from the latter family died at the age of 10 . Besides MECP2, there are four other genes duplicated in one or more families that are already involved in a specific phenotype. Loss-of function mutations in $S L C 6 A 8$ cause the creatine deficiency syndrome (OMIM 300352), which is characterized by MR, epilepsy, and expressive speech and language delay. ${ }^{11}$ SLC6A 8 is duplicated in family $\mathrm{D}$ and F. In patients from these two families, creatine levels in urine and spinal fluid were normal. In addition, the phenotype does not seem to be different as compared with the other patients, although brachycephaly was only noted in patients from these two families. However, brachycephaly is a common consequence of hypotonia and is not always present in patients with a SLC6A8 duplication. ${ }^{4}$ Loss-of-function mutations in L1CAM result in hydrocephalus, MASA syndrome (mental retardation, aphasia, shuffling gait, and adducted thumbs), and spastic paraplegia. ${ }^{12}$ Except for mental retardation, the characteristics of patients with L1CAM loss-of-function mutations were not present in any of the patients with a duplication of L1CAM. In addition, L1CAM is not $\mathrm{X}$-inactivated, ${ }^{13}$ which indicates that this gene is probably not dosage sensitive. FLNA gain-offunction mutations cause otopalatodigital syndrome I (OMIM 311300) or II (OMIM 304120), frontometaphyseal dysplasia (OMIM 305620), or Melnick-Needles syndrome (OMIM 309350). ${ }^{14}$ The symptoms between patients with MECP2 duplications and these four syndromes do not overlap, except for the presence of mental retardation. This shows that duplications of FLNA do not have the same effect as the gain-of-function mutations. Of note, FLNA is $\mathrm{X}$-inactivated, ${ }^{13}$ which indicates that the expression of this gene is dosage sensitive. FLNA loss-of-function mutations cause periventricular heterotopia (OMIM 300049), ${ }^{15}$ a cerebral cortical neuron migration disorder that results primarily in seizures that do not respond to treatment. ${ }^{16}$ However, drug-resistant epilepsy was not restricted to patients from family B and F, who have a FLNA duplication, which indicates that it is unlikely that duplication of solely FLNA is causing the epilepsy. GDI1 loss-of-function mutations cause non-specific $\mathrm{XLMR}^{17}$ and $G D I$ is X-inactivated. ${ }^{13}$ Moreover, duplications of GDI1 alone result in moderate MR and microcephaly. ${ }^{18}$ GDI1 is duplicated only in family F. Interestingly, this is the family with the severest phenotype and the only one in which microcephaly is described in one of the two patients. Including the two patients from family $\mathrm{F}$, five out of the eight patients with Xq28 duplication of whom the duplication is described in sufficient detail to be sure that GDI1 is included, have microcephaly. ${ }^{2,4,7,10}$ This supports a correlation between GDI1 duplications and microcephaly. Moreover, the reversed correlation, that is, patients with microcephaly have a GDI1 duplication, is true in five out of the six cases.

The main consistent clinical features in patients with a MECP2 duplication are severe mental retardation, infantile hypotonia, progressive spasticity, seizures, absent speech and recurrent infections. ${ }^{2}$ In the current study, all 13 affected males had infantile hypotonia and moderate to severe mental retardation. In addition, ataxia or an ataxic gait was described in almost all our patients, while it was not recognized as a symptom of the MECP2 duplication phenotype before. In two patients pyramidal signs were present, but these developed rather late and were definitely not present at the onset of the disease. Seizures were observed in $54 \%$ of the patients. Remarkably, the epilepsy was drug resistant in families A, B and C, which was also noted in several previously reported male patients with a MECP2 duplication., ${ }^{5,6}$ In family A, epilepsy was also observed in unaffected family members, although the severity of the seizures was significantly milder in the unaffected individuals as compared with the male patients carrying MECP2 duplications. The prevalence of infections in our patients is $23 \%$, which is much lower in comparison to the $80 \%$ described in previously published work (Table 2). This indicates that patients with Xq28 duplications that include MECP2 and IRAK1 might be less prone to infections than thought earlier. On the other hand, it is also possible that infections during infancy are not always reported. Previously, microcephaly was reported in 36\% of the patients with a MECP2 duplication, whereas in our study only one patient had microcephaly. Moreover, two male patients from the same family presented with macrocephaly. Del Gaudio et al ${ }^{4}$ described also one patient with macrocephaly, but his phenotype cannot be compared to that of our two patients, because he had three copies of MECP2. Our data suggests that microcephaly is not a consistent feature of patients with MECP2 duplications. Cerebral atrophy is common in our patients and present in six out of the eight tested patients. This could be a result of epilepsy, ${ }^{19}$ but only four of the examined 
Table 2 Clinical description of the MR patients with a MECP2 duplication

\begin{tabular}{|c|c|c|c|c|c|c|c|c|c|c|c|c|c|c|c|c|}
\hline \multirow{2}{*}{$\begin{array}{l}\text { Family } \\
\text { Patient }\end{array}$} & \multicolumn{2}{|c|}{$A$} & \multicolumn{4}{|c|}{$B$} & \multicolumn{2}{|c|}{$C$} & \multirow{2}{*}{$\begin{array}{c}D \\
I I-1\end{array}$} & \multicolumn{2}{|c|}{$E$} & \multicolumn{2}{|c|}{$F$} & \multirow[b]{2}{*}{$\begin{array}{l}\text { This report } \\
\mathrm{n} / \mathrm{N}\end{array}$} & \multirow{2}{*}{\multicolumn{2}{|c|}{$\begin{array}{l}\text { Literature Total } \\
\mathrm{n} / \mathrm{N}^{\mathrm{a}} \quad \text { (\%) }\end{array}$}} \\
\hline & $1 I I-7$ & $111-9$ & $11-7$ & III-1 & III-2 & III-5 & $I I-1$ & $11-2$ & & $1 /-1$ & $11-2$ & $1 /-2$ & $1 /-3$ & & & \\
\hline \multicolumn{17}{|l|}{ Main } \\
\hline $\begin{array}{l}\text { Age of last } \\
\text { examination (years) }\end{array}$ & 14 & 7 & 15 & 18 & 10 & 6 & 23 & 23 & 8 & 11 & 8 & 9 & 6 & & & \\
\hline $\begin{array}{l}\text { Moderate to severe } \\
\text { MR }\end{array}$ & + & + & + & + & + & + & + & + & + & + & + & + & + & $13 / 13$ & $63 / 63$ & 100 \\
\hline Infantile hypotonia & + & + & + & + & + & + & + & + & + & + & + & + & + & $13 / 13$ & $57 / 57$ & 100 \\
\hline $\begin{array}{l}\text { Age of walking } \\
\text { (years) }\end{array}$ & 3.3 & 2.5 & 2.5 & 2.5 & 2 & ND & 2 & 2 & 4 & 3 & 3 & 6 & 3 & & & \\
\hline Absent speech & + & - & + & + & + & + & + & + & + & + & - & + & - & $10 / 13$ & $35 / 42$ & 82 \\
\hline $\begin{array}{l}\text { Progressive } \\
\text { spasticity }\end{array}$ & + & + & + & - & - & - & + & - & - & - & - & + & + & $6 / 13$ & $19 / 22$ & 71 \\
\hline Recurrent infections & - & - & - & - & - & - & + & - & + & - & - & + & - & $3 / 13$ & $47 / 58$ & 70 \\
\hline Seizures & + & - & + & + & + & - & + & - & - & + & - & + & - & $7 / 13$ & $29 / 58$ & 51 \\
\hline Ataxia/ataxic gait & + & + & + & + & + & + & + & + & ND & + & ND & ND & ND & $10 / 10$ & - & - \\
\hline MRI abnormalities & + & ND & + & + & + & ND & ND & ND & + & - & - & + & + & $6 / 8$ & $2 / 3$ & - \\
\hline $\begin{array}{l}\text { Death at }<25 \text { years } \\
\text { of age }\end{array}$ & - & - & - & - & - & - & - & - & - & - & - & + & - & $1 / 13$ & $19 / 37$ & 40 \\
\hline \multicolumn{17}{|l|}{ Facial abnormalities } \\
\hline Microcephaly & - & - & - & - & - & - & - & - & - & - & - & + & - & $1 / 13$ & $22 / 58$ & 32 \\
\hline Macrocephaly & - & - & - & - & - & - & + & + & - & - & - & - & - & $2 / 13$ & $0 / 58$ & 3 \\
\hline Brachycephaly & - & - & - & - & - & - & - & - & + & - & - & + & + & $3 / 13$ & $13 / 38$ & 31 \\
\hline Large ears & + & + & + & + & + & + & + & + & - & - & - & + & + & $10 / 13$ & $13 / 38$ & 45 \\
\hline Flat midface & + & + & - & - & - & - & + & + & - & - & - & + & + & $6 / 13$ & $11 / 35$ & 35 \\
\hline Broad nasal root & - & - & + & + & + & + & - & - & - & + & + & + & + & $8 / 13$ & $7 / 38$ & 29 \\
\hline Hypertelorism & - & - & - & - & - & - & - & - & - & - & - & + & + & $2 / 13$ & $6 / 35$ & 17 \\
\hline \multicolumn{17}{|c|}{ Other congenital abnormalities } \\
\hline $\begin{array}{l}\text { Swallowing } \\
\text { problems }\end{array}$ & - & - & + & - & + & - & - & - & - & - & - & + & - & $3 / 13$ & $16 / 19$ & 59 \\
\hline $\begin{array}{l}\text { Genital } \\
\text { abnormalities }\end{array}$ & + & - & - & - & - & - & - & - & - & - & - & - & - & $1 / 13$ & $24 / 38$ & 49 \\
\hline $\begin{array}{l}\text { Digital } \\
\text { abnormalities }\end{array}$ & - & - & + & + & + & + & - & - & + & - & - & + & - & $6 / 13$ & $16 / 38$ & 43 \\
\hline
\end{tabular}

a $2-8,10$.

$\mathrm{ND}=$ not determined.

Table 3 Incidence of MECP2 duplications in males with MR selected by different criteria

\begin{tabular}{|c|c|c|c|c|}
\hline Selection criteria & Number of male patients & Number of MECP2 duplications & Frequency (\%) & Reference \\
\hline \multicolumn{5}{|l|}{ Phenotype } \\
\hline MR and spasticity & 17 & 3 & 17.6 & Van Esch et $a l^{2}$ \\
\hline Severe encephalopathy & 134 & 3 & 2.2 & This study \\
\hline MECP2 testing ${ }^{a}$ & 122 & 2 & 1.6 & Gaudio et $a t^{4}$ \\
\hline Chromosomal imbalances $^{b}$ & 1380 & 5 & 0.4 & Del Gaudio et $\left.a\right|^{4}$ \\
\hline \multicolumn{5}{|l|}{ Genotype } \\
\hline Linkage to $\mathrm{Xq} 28$ & 17 & 2 & 11 & Friez et $a f^{5}$ \\
\hline X-linked inheritance & 283 & 3 & 1.1 & This study \\
\hline
\end{tabular}

${ }^{\text {a }}$ atients sent to a diagnostic centre for MECP2 mutation screening; no further information was disclosed by the authors.

${ }^{\mathrm{b}}$ Males and females screened using a targeted microarray for disease relevant regions for deletions and duplications.

patients had both epilepsy and cerebral atrophy, which suggests that these symptoms are not related $a$ priori. Based on the available MRI data, we could not determine a more specific cerebral phenotype, but it would be interesting to delineate such a correlation in an additional study. In our study, distinct facial features such as large ears and broad nasal root are frequently observed in patients, which suggests that there might also be a specific facial appearance associated with MECP2 duplications. Combining all data, severe mental retardation and infantile hypotonia are 
the two core features of patients with duplications of MECP2. Absence of speech, seizures, progressive spasticity, recurrent infections, and possibly ataxia present in various combinations, further define the clinical phenotype.

At present, 37 families have been reported with duplications in the $\mathrm{Xq} 28$ region including $M E C P 2 .^{2-8,10}$ In addition, genomic segments proximal to the MECP2 gene have been duplicated either to or from the autosomes 2 , 10, 16 and 22..$^{20,21}$ Examination of the Xq28 duplication end points in 16 families did not provide any indication of a common mechanism for these genomic rearrangements. ${ }^{22}$ Non-allelic homologues recombination was not involved in any of these duplications, although eight of the 32 break points coincided with low-copy repeats. Nevertheless, the presence of numerous repeats in the Xq28 region could induce genomic instability. In one patient, non-homologues end joining was demonstrated. ${ }^{22}$ For two other patients, a two-step mechanism was suggested in which a part of Xq28 is inserted near MECP2, which is subsequently followed by breakage-induced replication with strand invasion of the normal sister chromatid resulting in a duplication of $M E C P 2$ and a second telomeric duplication. Taken together, these data indicate that there are multiple mechanisms by which copy number changes can occur in Xq28, showing that this is a fragile genomic region in general.

Our results underline the importance of screening for MECP2 gene duplications in male patients with moderate to severe mental retardation. In Table 3 , the recently published data on the number of duplications found in different groups of patients are summarized. Patients selected for the specific MECP2 duplication phenotype result in a mutation detection rate as high as $17 \% .^{2}$ As our study shows, in male patients with severe encephalopathy, the mutation frequency is still more than $2 \%$. In male patients referred for MECP2 mutation analysis in regular DNA diagnostics, this is $1.6 \%{ }^{4}$ This group of patients will overlap for a large part with our patients as male patients referred for MECP2 mutation analysis usually have (progressive) neurological symptoms as well. Even in a group of male and female patients with a phenotype that is suspect for a chromosomal rearrangement, MECP2 duplications were identified in $0.36 \%$ of the cases. ${ }^{4}$ Analysis of MR patients with linkage to Xq28, regardless of the specific phenotype, showed that the incidence is $11 \%{ }^{5}$ and here we show that analysis of patients with XLMR without a specific linkage interval still results in a detection frequency of $1 \%$ for MECP2 duplications. The mutation frequency of $M E C P 2$ duplications is among the highest of the known X-linked mental retardation genes. ${ }^{23}$ Therefore, we propose to implement DNA copy number testing for the MECP2 gene in the current diagnostic testing in all male patients with moderate to severe mental retardation accompanied by (progressive) neurological symptoms.

\section{Acknowledgements}

We thank the members of the families investigated for their invaluable contribution to this study.

\section{References}

1 Kleefstra T, Brunner HG, Amiel J et al: Loss-of-function mutations in euchromatin histone methyl transferase 1 (EHMT1) cause the 9q34 subtelomeric deletion syndrome. Am J Hum Genet 2006; 79: 370-377.

2 Van Esch H, Bauters M, Ignatius J et al: Duplication of the MECP2 region is a frequent cause of severe mental retardation and progressive neurological symptoms in males. Am J Hum Genet 2005; 77: 442-453.

3 Ariani F, Mari F, Pescucci C et al: Real-time quantitative PCR as a routine method for screening large rearrangements in Rett syndrome: Report of one case of MECP2 deletion and one case of MECP2 duplication. Hum Mutat 2004; 24: 172-177.

4 del Gaudio D, Fang P, Scaglia F et al: Increased MECP2 gene copy number as the result of genomic duplication in neurodevelopmentally delayed males. Genet Med 2006; 8: 784-792.

5 Friez MJ, Jones JR, Clarkson K et al: Recurrent infections, hypotonia, and mental retardation caused by duplication of MECP2 and adjacent region in Xq28. Pediatrics 2006; 118: e1687-e1695.

6 Meins M, Lehmann J, Gerresheim F et al: Submicroscopic duplication in Xq28 causes increased expression of the MECP2 gene in a boy with severe mental retardation and features of Rett syndrome. J Med Genet 2005; 42: e12.

7 Smyk M, Obersztyn E, Nowakowska B et al: Different-sized duplications of $\mathrm{Xq} 28$, including MECP2, in three males with mental retardation, absent or delayed speech, and recurrent infections. Am J Med Genet B Neuropsychiatr Genet 2008; 147B: 799-806.

8 Sanlaville D, Prieur M, de Blois MC et al: Functional disomy of the Xq28 chromosome region. Eur J Hum Genet 2005; 13: 579-585.

9 Miller SA, Dykes DD, Polesky HF: A simple salting out procedure for extracting DNA from human nucleated cells. Nucleic Acids Res 1988; 16: 1215.

10 Lugtenberg D, de Brouwer AP, Kleefstra T et al: Chromosomal copy number changes in patients with non-syndromic X-linked mental retardation detected by array CGH. J Med Genet 2006; 43: $362-370$.

11 Rosenberg EH, Almeida LS, Kleefstra T et al: High prevalence of $S L C 6 A 8$ deficiency in X-linked mental retardation. Am J Hum Genet 2004; 75: 97-105.

12 Jouet M, Rosenthal A, Armstrong $G$ et al: X-linked spastic paraplegia (SPG1), MASA syndrome and X-linked hydrocephalus result from mutations in the L1 gene. Nat Genet 1994; 7: 402-407.

13 Carrel L, Willard HF: X-inactivation profile reveals extensive variability in X-linked gene expression in females. Nature 2005; 434: 400-404.

14 Robertson SP, Twigg SR, Sutherland-Smith AJ et al: Localized mutations in the gene encoding the cytoskeletal protein filamin A cause diverse malformations in humans. Nat Genet 2003; 33: $487-491$.

15 Fox JW, Lamperti ED, Eksioglu YZ et al: Mutations in filamin 1 prevent migration of cerebral cortical neurons in human periventricular heterotopia. Neuron 1998; 21: 1315-1325.

16 Huttenlocher PR, Taravath S, Mojtahedi S: Periventricular heterotopia and epilepsy. Neurology 1994; 44: 51-55.

17 D'Adamo P, Menegon A, Lo Nigro C et al: Mutations in GDI1 are responsible for X-linked non-specific mental retardation. Nat Genet 1998; 19-6: 134-139.

18 Madrigal I, Rodriguez-Revenga L, Badenas C et al: MLPA as first screening method for the detection of microduplications and microdeletions in patients with X-linked mental retardation. Genet Med 2007; 9: 117-122. 
19 Briellmann RS, Wellard RM, Jackson GD: Seizure-associated abnormalities in epilepsy: evidence from MR imaging. Epilepsia 2005; 46: 760-766.

20 Eichler EE, Budarf ML, Rocchi $\mathrm{M}$ et al: Interchromosomal duplications of the adrenoleukodystrophy locus: a phenomenon of pericentromeric plasticity. Hum Mol Genet 1997; 6: 991-1002.

21 Horvath JE, Schwartz S, Eichler EE: The mosaic structure of human pericentromeric DNA: a strategy for characterizing complex regions of the human genome. Genome Res 2000; 10: 839-852.

22 Bauters M, Van EH, Friez MJ et al: Non-recurrent MECP2 duplications mediated by genomic architecture-driven DNA breaks and break-induced replication repair. Genome Res 2008; 18: $847-858$.

23 de Brouwer AP, Yntema HG, Kleefstra T et al: Mutation frequencies of X-linked mental retardation genes in families from the EuroMRX consortium. Hum Mutat 2007; 28: 207-208. 